\title{
EDITORIAL:
}

\section{SOFTWARE SURVEY SECTION}

The introduction of the new Software Survey Section to INSECT SCIENCE AND ITS APPLICATION is to encourage the open exchange of information on software programmes unique to our professional field. With the rapid penetration of computers into academic and industrial institutions has come a parallel increase in the number of scientists and researchers designing their own software. The existence of much of this software remains unknown even to those of us who could most benefit from its use. We believe that it is of vital importance to our readers that such information be made available. We also believe that a professional journal is the best place to share such information. Your contribution would be most welcome. 
Please complete the form and send it to the Editor-in-Chief, professor Thomas R. Odhiambo, Insect Science and Its Application, P.0. Box 72913, Nairobi, Kenya, East Africa

Software Package:

Contributor/Address:

Brief Description:

Field of Application:

Potential Users: 


\section{INSECT SCIENCE AND ITS APPLICATION}

The International Journal of Tropical Insect Science

\section{AIMS AND SCOPE}

Insect Science and its Application deals comprehensively with all aspects of scientific research targeted on tropical insects (and related arthropods), and the application of new discoveries and innovations to such diverse fields as pest and vector management and the use of insects for human welfare.

A distinctive feature of the journal is its multi- and interdisciplinary nature, which transcends the traditional boundaries of entomology.

Its second feature is its concentration on the recording and reviewing of the progress of insect science in the tropical and subtropical regions of the world. Thus, without excluding any area of the wideranging field encompassed by insect science, the journal will accept manuscripts in environmental physiology, the regulation of development and reproduction, population modelling, chemical ecology, natural products chemistry, plant resistance, host-insect relations, behaviour of tropical pest species, epidemiology of tropical diseases, vector biology, pest and vector management research, insect pathology, entomo-meteorology, insects in relation to farming systems, forest entomology, social insects and arthropods, and the use and farming of insects. It is the intention of the Editors to have the manuscripts published rapidly, consistent with the needs of quality control.

In addition to articles of original research, the journal also publishes mini-reviews articles, announcements and reports of meetings, book reviews, new patents, obituaries of prominent scientists and software survey. Each regular issue of the journal usually contains a short review article on a critical or rapidly developing area of tropical insect science; normally, the Editors will have invited an author to contribute such a mini-review.

Insect Science and Its Application is an international journal, pursuing its own independent policy through its editorial staff and the Editorial Advisory Board, which is internationally appointed. Its sponsors, the ICIPE and the African Association of Insect Scientists (AAIS), do not intervene in editorial matters.

\section{INSTRUCTIONS TO AUTHORS}

For indications of the design of papers, the author should consult a recent issue of the journal. The following paragraphs are provided as guidelines for the preparation and submission of manuscripts.

\section{All papers for publication in Insect} Science and Its Application should be submitted directly to Professor Thomas R. Odhiambo, Editor-in-Chief, Insect Science and Its Application, ICIPE Science Press, P.O. Box 72913, Nairobi, Kenya Papers should be mailed in a strong envelope, preferably linen, as they will otherwise arrive in a damaged condition.

2. Papers should be typed in English or French, and be original contributions in the field of tropical insect science. Each paper should have a summary in the form of an abstract in both English and French.

3. Submission of a paper implies that it has not been published previously, that it is not under consideration for publication elsewhere, and that if accepted for Insect Science and Its Application the authors will transfer copyright to the ICIPE Science Press of the International Centre of Insect Physiology and Ecology. Manuscripts and illustrations become the property of the journal.

4. There is no page charge for papers accepted for publication.

5. Manuscripts and illustrations must be submitted in triplicate (original and two copies) to ensure efficient refereeing. In the case of multiple authorship, the authors should indicate who is to receive correspondence and the correct address for the mailing of proofs.

6. Manuscripts must be typewritten with double spacing (including the reference list), with wide margins, and on one side of the paper only. Authors are requested to keep their communications as concise as possible. Footnotes should be avoided, and italics should not be used for emphasis. A running head of not more than 30 letters should be supplied. 
7. The manuscript should contain the following features:

Title: This should be followed by the author's name and full address.

Abstract containing a brief summary of the contents, and conclusions of the paper. It should not be longer than 200 words, and should be supplied in both English and French.

Key Words A short list of key words should be provided for rapid scanning of the contents of the paper and use in compiling the Index to the completed volume of the journal.

Introduction should contain a brief survey of the relevant literature and the reasons for doing the work.

\section{Materials and Methods Sufficient}

information should be given to permit repetition of the experimental work by other workers. The technical description of methods should be given only when such methods are new.

Results should be presented concisely. Only in exceptional cases will it be permissible to present the same set of results in both a table and a figure. The results section should not be used for discussion.

Discussion should be separate from the Results section, and should deal with the significance of the results and their relationship to the object of the work. Comparison with relevant published work should be made, and conclusions drawn. Acknowledgements Only pertinent acknowledgements should be cited. Reference The Harvard system will be followed. References should be detailed in the following order: Authors' names and initials, date of publication (in brackets), the title of the article, the name of the journal as abbreviated in the World List of Scientific Periodicals (4th edn. 1964), the volume, and the first and last pages of the article, e.g. Delobel A.G.L. (1983) Influence of temperature and host plant condition on preimaginal development and survival in sorghum shootfly, Atherigona soccatta. Insect Sci. Applic. $4,327-335$.

For books, the author's names, date of publication, title, edition, page reference, publisher's name and the place of publication should be given, e.g.
Zurfleuh R.C. (1976) Phenylethers as insect growth regulators: laboratory and field experiments. In Juvenile Hormones (Edited by Gilbert L.L.), pp. 61-74. Plenum Press, New York.

Within the text, references should be given as Unnithan (1981) or (Unnithan, 1981). When a citation includes more than two authors, e.g. Ochieng', Onyango and Bungu, the paper should be referred to in the text as Ochieng' et al., provided that this is not ambiguous. If there are only two authors, they should be referred to as Ochieng' and Onyango. If papers by the same authors in the same year are cited, they should be distinguished by letters (a,b,c, etc.).

Reference to papers "in press" must mean that the article has been accepted for publication and should be given as follows:

Darlington J.P.E.C. (1988) Primary reproductives and royal cells of the termite, Macrotermes michaelseni. Insect Sci. Applic. In press. References to "personal communication" and unpublished work are permitted in the text only.

8. Illustrations. All necessary original illustrations should accompany the manuscript, but should not be inserted in the text. All photographs, graphs and diagrams should be numbered consecutively in arabic numerals in the order in which they are referred to in the text.

Glossy photographs or positive prints (not slides or X-ray negatives) should be sent, unmounted wherever possible, and should be restricted to the minimum necessary.

Charts, graphs or diagrams should be drawn boldly in black ink on good quality white paper or card. Lettering to appear on the illustrations should be given in full and should be of sufficient size to withstand considerable reduction, where necessary. Alternatively, lettering may be shown on a rough overlay and will be inserted by the printer.

Illustrations should not be larger than $24 \times 30 \mathrm{~cm}$, or they may be damaged in the post. On the back of each illustration should be indicated the author's name, the figure number (in arabic numerals), and the top of the illustration, where this is not clear.

The following symbols should be used on line drawings as they are readily available to 
the printer: $\Delta \triangle \nabla \nabla \mathbf{D} \square \times+00$.

Legends to figures should be typed on a separate sheet, not under the figures, and should give sufficient data to make the illustration comprehensible without reference to the text.

Magnification of photographs and illustrations should be indicated by an appropriate scale bar and not in the legend. This practice obviates the complications which arise through change of size in reproduction.

9. Tables should be constructed so as to be intelligible without reference to the text, numbered in arabic numerals, and typed on separate sheets. Every Table should be provided with an explanatory caption, and each column should carry an appropriate heading. Units of measurement should always be indicated clearly. All Tables and Figures must be referred to in the text in numerical order.

10. Only standard abbreviations should be used. Where specialized abbreviations are used, the name should be given initially in full with the abbreviation indicated in parentheses.

11. The common and Latin names should be given for all species used in the investigation, although taxonomic affiliation and authority should not be provided in the title.

12. Page proofs will be sent to the author by the printer of the ICIPE Science Press. They will already have been proof read by the typesetter for printer's errors; but it is the author's responsibility to ensure that the proof contains no errors. Correction to proofs should be restricted to printer's errors only. Other than these, substantial alterations will be charged to the author. Proofs should be returned to the ICIPE Science Press within $48 \mathrm{hr}$ of receipt for final preparation for the printer. Failure to meet this deadline may result in the inadvertent inclusion of errors in the published article. 


\begin{abstract}
AUTHOR CHECKLIST
It is strongly recommended that authors submitting manuscripts for publication should make a copy of this checklist and submit it with their manuscripts to the Editor-in-Chief. This will ensure that their manuscript is in the correct format, and should make for more rapid processing and publication.
\end{abstract}

\title{
General
}

Original and two exact copies of manuscript sent, one copy kept.

Pages numbered throughout

Separate pages for references, tables and figure legends (all double spaced)

Name and address for correspondence clearly indicated, particularly in the case of multiple author manuscripts. . .......

Manuscript despatched in strong envelope

\section{Text}

Cover page (p. 1) with: (a) title; (b) full postal address; and (c) running title at foot

Abstract (including authors and title) and index key words on separate page (p. 2)

Abstract submitted in both English and French

Citation of references in text conforms to specification in Instructions to Authors

Joint authors quoted as Macharia and Mueke; i.e. not Macharia \& Mueke. .

References in text and in reference list correspond exactly

Journal titles given in full and underlined (or in italics)...

First and last pages of articles in references quoted

Manuscript with paper clips, not stapled

Measurements in metric system.

\section{Figures}

Size of Figures conforms to specification in Instructions to Authors .

All magnifications indicated by scale bars, not in the legend.

Author's name and figure number on back of all Figures

Legend for Figures on separate pages

Abbreviations for Figures fully listed and explained

I have checked that the submitted manuscript conforms with the format outlined above.

(Author)

(Date of despatch) 


\section{Insect Science and Its Application}

The International Journal of Tropical Insect Science

\section{PRE-PUBLICATION SUBSCRIPTION RATES}

Institutional:

$\$ 95$

ICIPE/AAIS Members: $\quad \$ 14$

Individual Members:

Individual with a

Subscribing Institution:

Please send your subscription requests to:

ICIPE SCIENCE PRESS

Subscription Department

P.O. Box 72913

NAIROBI, Kenya

East Africa 